\title{
Artificial Aging Experiments of Neat and Contaminated Engine Oil Samples
}

\author{
András Lajos Nagy ${ }^{1, * \mathbb{C}}$, Jan Rohde-Brandenburger ${ }^{1}$ and Ibolya Zsoldos ${ }^{2}$ \\ 1 Department of Internal Combustion Engines and Propulsion Technology, Széchenyi István University, \\ 9026 Győr, Hungary; jan.rohde-brandenburger@audi.hu \\ 2 Department of Material Technology, Széchenyi István University, 9026 Győr, Hungary; zsoldos@sze.hu \\ * Correspondence: nagy.andras1@sze.hu
}

\section{check for}

updates

Citation: Nagy, A.L.;

Rohde-Brandenburger, J.; Zsoldos, I. Artificial Aging Experiments of Neat and Contaminated Engine Oil

Samples. Lubricants 2021, 9, 63.

https://doi.org/10.3390/lubricants 9060063

Received: 4 May 2021

Accepted: 17 June 2021

Published: 19 June 2021

Publisher's Note: MDPI stays neutral with regard to jurisdictional claims in published maps and institutional affiliations.

Copyright: (c) 2021 by the authors. Licensee MDPI, Basel, Switzerland. This article is an open access article distributed under the terms and conditions of the Creative Commons Attribution (CC BY) license (https:// creativecommons.org/licenses/by/ $4.0 /)$.

\begin{abstract}
This study highlights how the results from an artificial engine oil aging method compare to used engine oil samples collected from a vehicle fleet. Additionally, this paper presents the effect of contaminating the oil during aging with synthetic fuel alternatives on the physical and chemical properties of artificially aged engine oil samples. A laboratory-scale artificial thermo-oxidative aging experiment was conducted on multiple samples of commercially available formulated fully-synthetic SAE 0W-30 engine oil. The goal of the experiment was to establish the validity of the artificially aged samples as well as the validity of the underlying process in reproducibly fabricating small batches of aged engine oil with comparable chemical and physical properties to real-life used oils. Eight samples were subjected to distinct load cases (temperature, air flow rate, sample volume and aging time). Six additional samples were subjected to an intermediate load case, with five of them contaminated with selected conventional fuels and novel automotive fuel candidates. Conventional oil analysis was conducted on each sample to determine oxidation, residual additive content, kinematic viscosity and total base number. Additionally, analysis results were compared to in-use engine oil samples through PCA. The resulting oil condition after aging is in accordance with independently published results in terms of zinc dialkyldithiophosphate content and kinematic viscosity. Contaminated aging with $\mathrm{OME}_{3-5}$ resulted in a drop in antioxidant content and elevated kinematic viscosity. Based on the comparison with in-use samples, artificial aging of $200 \mathrm{~mL}$ engine oil at $180{ }^{\circ} \mathrm{C}$ with $1 \mathrm{~L} / \mathrm{min}$ air flow for $96 \mathrm{~h}$ can produce similar oil conditions as mixed vehicle use for $7000 \mathrm{~km}$.
\end{abstract}

Keywords: engine oil; artificial aging; method development; oil analysis

\section{Introduction}

Electrification in the automotive industry is a globally emerging tendency, with more and more automakers committing to introducing an increasing amount of electric powertrains in their commercial line-up in the near future [1-3]. However, existing vehicle fleets and special applications (e.g., off-road, off-grid and heavy-duty) still rely heavily on internal combustion engines, which require appropriate lubrication throughout their service life. Reaching set targets [4] for the global reduction of harmful emissions requires a systematic approach, which incorporates novel fuel technologies that are backwards compatible with current internal combustion powertrains. Lubricants in general are manufactured from a base oil and a tailor-made additive package, which ensures long-term functionality and stable lubrication properties. Modern engine oils are predominantly fully synthetic lubricants, which use a poly-alpha-olefin as a base fluid and a selection of property-enhancing functional additives, e.g., antioxidants, corrosion inhibitors, viscosity modifiers, antifoaming agents, biocide agents, pressure tolerance modifiers, friction modifiers and antiwear additives $[5,6]$. The complex chemical system of an engine oil continuously changes during operation, with certain compounds oxidizing due to the elevated operation temperature, or cracking under the high shear load between bearing surfaces [7]. Fuel dilution and combustion by-products can also contribute to an expedited deterioration of the lubricant 
by reacting with certain additive compounds [8]. Hence, a comprehensive methodology for testing and assessing alternative combustion fuels in terms of tribological compatibility is necessary to ensure long-term operation and avoid damage and down-time of high-value machinery. A previous study established the applicability of the developed equipment [9] as well as the reproducibility of the aging process [10] for artificial aging of ultra-low viscosity engine oil samples. This study aims to show the validity of the artificially aged samples in terms of viscosity and oxidation properties compared to oil samples from a fleet experiment. Additionally, this paper also presents the effect of contaminating the oil during aging with synthetic fuel alternatives on the physical and chemical properties of artificially aged engine oil samples.

\section{Materials and Methods}

An artificial lubricant aging system was developed in order to simulate engine oil degradation. The system consists of an aging rig and corresponding methodology for thermo-oxidative degradation. A detailed description of the system is presented in [10]. Details of the aging experiments are presented in Section 2.1. Engine oil samples were collected and sent for chemical analysis to determine the effect of artificial aging on key oil properties. Analysis methods are presented in Section 2.2. A comprehensive field experiment was conducted on a passenger car fleet of 12 vehicles in order to gain a better understanding of in-use engine oil aging. Detailed findings regarding used engine oil chemistry have been published in an extensive research article [11], therefore will only be presented very briefly. The fundamentals of the fleet study are described in Section 2.3.

\subsection{Artificial Aging}

An oil aging experiment including 8 distinct thermo-oxidative load cases was performed on Shell Helix Ultra ECT C2/C3 0W-30 engine oil samples. A fractional-factorial parametric study was set up using 4 variables at 2 levels each according to Table 1 . Sample temperature, air flow rate and sample volume were varied independently, with aging time being confounded to temperature and flow rate. Sample names correspond to the levels of independent variables. Samples were subjected to a cyclic thermal degradation process composed of $12 \mathrm{~h}$ heating and $12 \mathrm{~h}$ accumulation phases. This cyclic thermo-oxidative aging procedure is based on a procedure developed by Singer et al. [12]. The system reaches a stable set point temperature under $120 \mathrm{~min}$ and is able to keep sample temperatures within $\pm 1.5^{\circ} \mathrm{C}$.

Table 1. Sample identifiers and corresponding parameter values for the parametric engine oil aging experiment.

\begin{tabular}{ccccc}
\hline Sample ID & $\begin{array}{c}\text { Temperature } \\
\left({ }^{\circ} \mathbf{C}\right)\end{array}$ & $\begin{array}{c}\text { Air Flow Rate } \\
(\mathbf{L} / \mathbf{m i n})\end{array}$ & $\begin{array}{c}\text { Sample Volume } \\
(\mathbf{m L})\end{array}$ & $\begin{array}{c}\text { Aging Time } \\
(\mathbf{h})\end{array}$ \\
\hline A4.122 & 160 & 2.5 & 200 & 96 \\
$\mathrm{~A} 4.121$ & 160 & 2.5 & 100 & 96 \\
$\mathrm{~A} 4.112$ & 160 & 1 & 200 & 192 \\
$\mathrm{~A} 4.111$ & 160 & 1 & 100 & 192 \\
$\mathrm{~A} 4.212$ & 180 & 1 & 200 & 96 \\
$\mathrm{~A} 4.211$ & 180 & 1 & 100 & 96 \\
$\mathrm{~A} 4.222$ & 180 & 2.5 & 200 & 192 \\
$\mathrm{~A} 4.221$ & 180 & 2.5 & 100 & 192 \\
\hline
\end{tabular}

A secondary study was carried out involving 5 contaminating agents (conventional fuels and novel automotive fuel candidates) with an identical initial oil quality to the parametric study. Contaminants were identified and selected based on a prior literature review on alternative fuels [13]. Artificial aging was conducted on $200 \mathrm{~mL}$ samples at $160^{\circ} \mathrm{C}$ with $2 \mathrm{~L} / \mathrm{min}$ air flow rate. After a $96 \mathrm{~h}$ preliminary aging procedure the samples were contaminated with $5 \mathrm{~mL}$ of the corresponding fuels. An additional $96 \mathrm{~h}$ aging procedure 
was executed, where a further $15 \mathrm{~mL}$ of the corresponding contaminant was added to each sample in three $5 \mathrm{~mL}$ doses after 24, 48 and $72 \mathrm{~h}$. Sample identifiers and corresponding contaminants are given in Table 2.

Both aging experiments were conducted in the Tribology Lab of the Department of Internal Combustion Engines and Propulsion Technology at Széchenyi University in Győr.

Table 2. Sample identifiers and corresponding contaminants for the contaminated engine oil aging experiment.

\begin{tabular}{ccc}
\hline Sample ID & $\begin{array}{c}\text { Contaminating } \\
\text { Agent }\end{array}$ & $\begin{array}{c}\text { Target Conc. } \\
v / v \%\end{array}$ \\
\hline A3.NOC & No contamination & 0 \\
A3.DMC & Dimethyl carbonate (DMC) & 10 \\
A3.OME & Oxymethylene dimethyl ether 3-5 (OME $3-5)$ & 10 \\
A3.MTH & Methanol (MTH) & 10 \\
A3.E25 & EN228 gasoline with 25\% ethanol (E25) & 10 \\
A3.R95 & EN228 gasoline, RON 95 & 10 \\
\hline
\end{tabular}

One major limitation of the presented experimental investigation is the lack of repetition of the artificial aging experiments. A previous study [10] has established a reproducibility with a relative deviation under $5 \%$ using the same reference oil, which was deemed to be acceptable. Hence, to maximize the achievable gain of experience with the budgetary constraints of the study, variety was chosen over repetition. A further limitation of the presented methodology is the lack of mechanical shear load, and the absence of metallic reagents during aging. These could contribute to a more realistic aging procedure, which can also consider viscosity changes due to shear thinning and the depletion of additives due to surface bonding and boundary layer development.

\subsection{Engine Oil Analysis}

Conventional oil analysis was performed on all samples after the completion of the aging experiments. Chemical analysis was carried out by the Austrian Excellence Center for Tribology (AC2T) in Wiener Neustadt. The following analytical methods and techniques were utilized to determine the chemical properties of each sample:

- Oxidation and nitration were determined through Fourier-transformed infrared spectroscopy (FTIR) using a custom method of determining the absorption peak height at $1720 \mathrm{~cm}^{-1}$ for oxidation and at $1630 \mathrm{~cm}^{-1}$ for nitration [8].

- $\quad$ Residual amounts of phenolic and aminic antioxidant (AO) as well as ZDDP antiwear additive compared to the initial amounts in the reference sample were determined through FTIR according to a custom method, based on absorption peak heights of $3650 \mathrm{~cm}^{-1}$ for phenolic AO and $1515 \mathrm{~cm}^{-1}$ for aminic AO as well as the highest intensity within the range 1020 to $920 \mathrm{~cm}^{-1}$ for ZDDP [8].

- $\quad$ Kinematic viscosity at $40{ }^{\circ} \mathrm{C}$ was measured by an SVM 3000 Stabinger viscometer according to [14] and calculation of the viscosity index according to [15].

- $\quad$ Total base number (TBN) values were determined according to [16] by potentiometric titration with perchloric acid utilizing a titrator equipped with an autosampler.

\subsection{Fleet Study}

An investigation of in-use engine oil aging was performed on a passenger car fleet of diverse models from a German manufacturer with 2-L four-cylinder turbocharged DISI (9 out of 12) and CIDI (3 out of 12) engines of various performance classes. Vehicles were grouped into two distinct categories regarding their range of usage:

- Vehicles categorized as short-range were restricted to be used solely inside the perimeter of a given controlled speed zone (i.e., a speed limit of $50 \mathrm{~km} / \mathrm{h}$ ). 
- Vehicles categorized as long-range were general-use passenger cars without any special restriction.

A factory standard oil change was performed on each vehicle before the start of the experiment. The vehicles were filled with a VW 504.00/507.00 compliant SAE 0W-30 grade fully synthetic engine oil, which has comparable properties and chemistry to the Shell reference oil used for the artificial aging experiments. Oil samples were taken at regular time intervals from every vehicle during the monitoring period. An intended sampling period of 1 month and a sampling distance of $2500 \mathrm{~km}$ were defined for shortand long-range vehicles, respectively. It should be mentioned that certain vehicles were taken for excessively long trips, which led to missed or late sample collection. In other cases, the driver ignored the request to bring the vehicle in for sample collection. A total of 46 in-use engine oil samples were collected throughout a 6 month time period. Collected used oil samples were analyzed through conventional (see Section 2.2) and advanced analytical methods.

Additional information regarding daily usage was collected through GPS vehicle fleet tracking. Vehicle speed and mileage values were registered every $5 \mathrm{~s}$ during each trip. The experiment was conducted with random ordinary drivers, who were not aware of their involvement. To respect general data protection regulations, no GPS coordinates were saved for analysis, nor was any other form of information collected that could be used to identify individual drivers or to profile their behavior.

The aim of the fleet study was to create a baseline for engine oil aging in modern highperformance vehicles under ordinary vehicle use conditions. Hence, a fleet comprising various chassis types and differing engine-power classes was commissioned to facilitate generalization of results. However, one main shortcoming of such an experimental design is the low reproducibility. An investigation in a strictly controlled environment could give better insight into the nuances of in-use oil aging and show how variations in, e.g., engine load, vehicle speed or environmental air temperature influence certain physical and chemical properties of the lubricant.

As detailed in [11], principal component analysis (PCA) was utilized to identify the main contributing factors and visualize relations between collected samples. A similar approach was taken to incorporate artificially aged samples into the analysis and determine the suitability of the aging procedure and apparatus for simulating in-vehicle engine oil degradation. Since only conventional oil analysis was conducted on the laboratory-aged samples, the following variables (features) were included in the PCA: oxidation, residual antiwear additive content (ZDDP), residual antioxidant additive content (phenolic and aminic), TBN, kinematic viscosity $\left(@ 40{ }^{\circ} \mathrm{C}\right.$ and $@ 100{ }^{\circ} \mathrm{C}$ ) and viscosity index (VI).

\section{Results and Discussion}

This section details findings regarding oil properties after each artificial aging experiment, as well as a comparative analysis of artificially aged and in-use engine oil samples. Results for the parametric and contaminated engine oil aging experiments are presented in Sections 3.1 and 3.2, respectively. Results for the aging experiments and the fleet study are compared and discussed in Section 3.3.

\subsection{Chemical Analysis Results-Parametric Aging Study}

Oxidation based on absorption peak height (Figure 1a) shows a clear increasing tendency with increasing temperature, aging time and air flow rate. Increasing the sample volume causes a drop in specific thermal and oxidative load, which also leads to decreased oxidation. As anticipated, no nitration or soot content was perceived by the FTIR measurement. Residual zinc dialkyldithiophosphate (ZDDP) antiwear additive content (Figure 1b) shows a significant drop in all cases compared to the reference sample $(100 \%)$. All samples exhibit a value of around 13-15\% antiwear content aside from the ones with the highest load $\left(180{ }^{\circ} \mathrm{C}\right.$ for $\left.192 \mathrm{~h}\right)$. These extreme load cases appear to completely deplete the antiwear 
additive content of the samples, with no measurable amount of ZDDP left in the samples after aging.

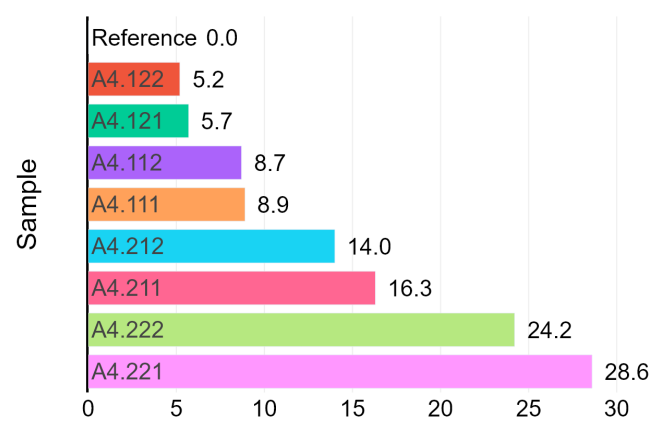

a) Oxidation $(\mathrm{A} / \mathrm{cm})$

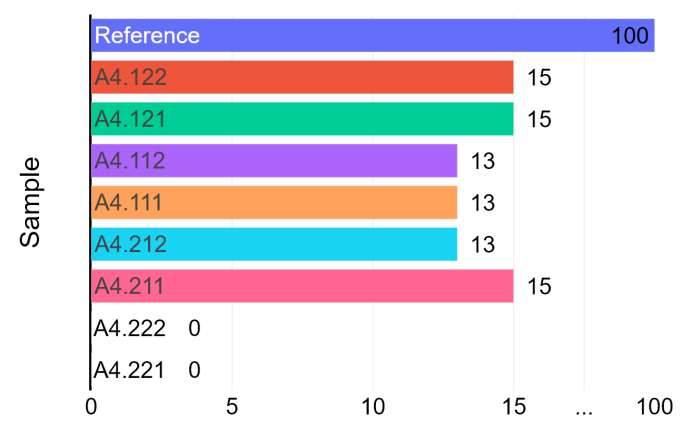

b) ZDDP residue (\%)

Figure 1. (a) Comparison of respective oxidation values after the parametric artificial aging experiment. (b) Comparison of respective residual antiwear additive (ZDDP) content values after the parametric artificial aging experiment. Reference: Shell Helix Ultra ECT C2/C3 0W-30.

Residual antioxidant content shows a gradual decrease compared to the reference oil sample. The amount of phenolic antioxidant residue (Figure $2 b$ ) is in accordance with the previous observation of overall oxidation and shows correlating tendencies for all samples. Regarding aminic antioxidant residues (Figure 2a), a slightly different trend can be observed. Sample volume and air flow rate appear to have less of an impact, while aging time causes seemingly minor variance at $160{ }^{\circ} \mathrm{C}$. At $180{ }^{\circ} \mathrm{C}$ aging time appears to be a prominent influencing factor, with around a $40 \%$ drop in values compared to $160{ }^{\circ} \mathrm{C}$ and another 30\% variance between 96 and $192 \mathrm{~h}$ samples.

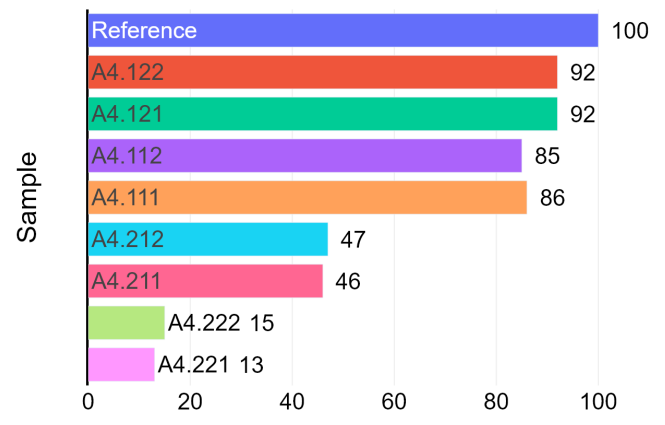

a) Aminic antioxidant residue (\%)

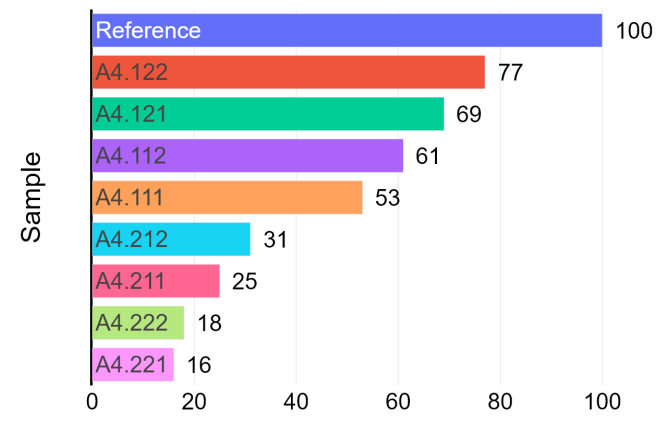

b) Phenolic antioxidant residue (\%)

Figure 2. (a) Comparison of respective aminic antioxidant additive residues after the parametric artificial aging experiment. (b) Comparison of respective phenolic antioxidant additive residues after the parametric artificial aging experiment. Reference: Shell Helix Ultra ECT C2/C3 0W-30.

Regarding kinematic viscosity at $40{ }^{\circ} \mathrm{C}$ (Figure 3a) each sample displays an increased value compared to the reference. Samples aged at $160{ }^{\circ} \mathrm{C}$ for 96 and $192 \mathrm{~h}$ show comparable values. Samples aged at $180{ }^{\circ} \mathrm{C}$ for $96 \mathrm{~h}$ exhibit similar values, whereas samples aged at $180{ }^{\circ} \mathrm{C}$ for $192 \mathrm{~h}$ show $71 \%$ to $132 \%$ increases. At $100{ }^{\circ} \mathrm{C}$ (Figure $3 \mathrm{~b}$ ) most values lie slightly below or around the reference oil's viscosity, whereas the two samples with the highest specific thermal load and longest aging time exhibit significant increases in kinematic viscosity values. Regarding viscosity index (Figure 4a), a highly similar tendency to aminic residual additives was established. 


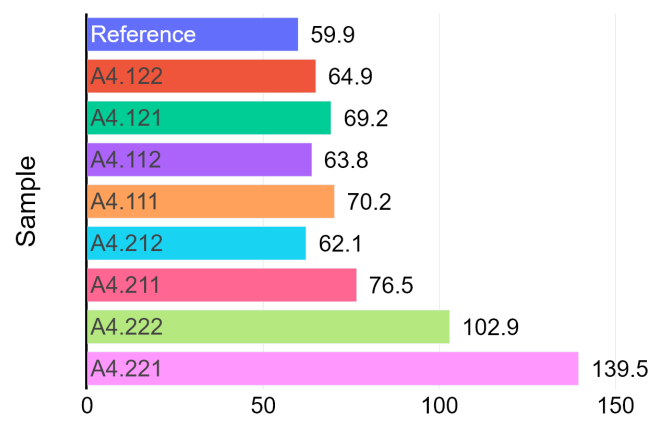

a) Kinematic viscosity $@ 40^{\circ} \mathrm{C}\left(\mathrm{mm}^{2} / \mathrm{s}\right)$

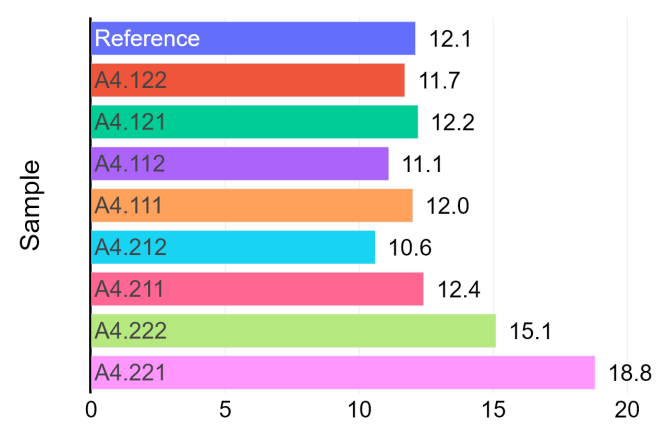

b) Kinematic viscosity @ $100^{\circ} \mathrm{C}\left(\mathrm{mm}^{2} / \mathrm{s}\right)$

Figure 3. (a) Comparison of kinematic viscosity at $40{ }^{\circ} \mathrm{C}$ after the parametric artificial aging experiment. (b) Comparison of kinematic viscosity at $100{ }^{\circ} \mathrm{C}$ after the parametric artificial aging experiment. Reference: Shell Helix Ultra ECT C2/C3 0W-30.

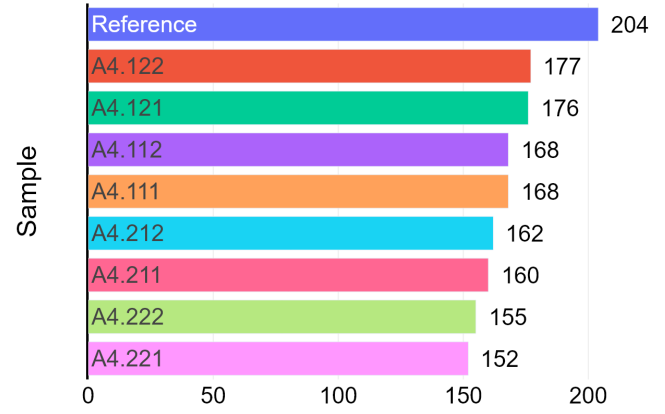

a) Viscosity Index (-)

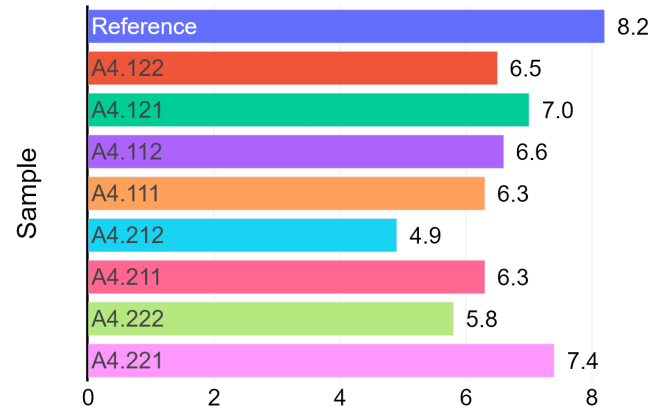

b) Total Base Number (mgKOH/g)

Figure 4. (a) Comparison of viscosity index after the parametric artificial aging experiment. (b) Comparison of total base number (TBN) after the parametric artificial aging experiment. Reference: Shell Helix Ultra ECT C2/C3 0W-30.

Total base number values display a moderate decrease (Figure $4 \mathrm{~b}$ ), with the most significant change of around $-41 \%$ at $180{ }^{\circ} \mathrm{C}$ after $96 \mathrm{~h}$. One aged sample shows an interesting outlier regarding TBN, with the lowest comparable decrease in TBN after $192 \mathrm{~h}$ at $180{ }^{\circ} \mathrm{C}$.

\subsection{Chemical Analysis Results_Contaminated Aging Study}

Contaminant type appears to have little effect on general oxidation (Figure 5a), with negligible differences between samples. Similarly to the previously presented results, no nitration or soot content was perceived by the FTIR measurement. Residual ZDDP content (Figure 5b) shows comparable values for all contaminated samples, which are in accordance with the findings of the parametric aging experiment.

Aminic (Figure 6a) and phenolic (Figure 6b) antioxidant content dropped in all samples during aging. A maximal difference of $5 \%$ phenolic antioxidant content can be established between samples with contaminants $\mathrm{OME}_{3-5}$ and methanol, which is marginal. Interestingly, contaminating the oil with $\mathrm{OME}_{3-5}$ during the experiment resulted in a significant drop in aminic antioxidant content compared to other samples. Oxymethylene ethers are known oxidizers and are investigated as diesel fuel additives $[17,18]$ for their ability to reduce the $\mathrm{NO}_{\mathbf{x}}$ soot trade-off in CIDI engines. The oxidative nature of $\mathrm{OME}_{3-5}$ could lead to a faster depletion of certain antioxidants in the engine oil. This phenomenon needs further investigation to understand the reaction pathways and products of OME-antioxidant interactions. 


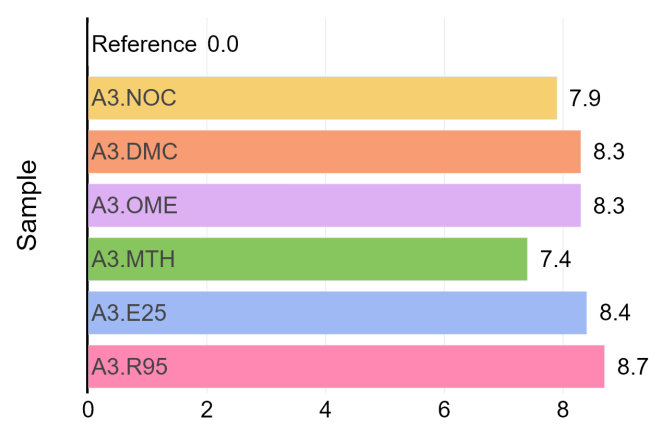

a) Oxidation $(\mathrm{A} / \mathrm{cm})$

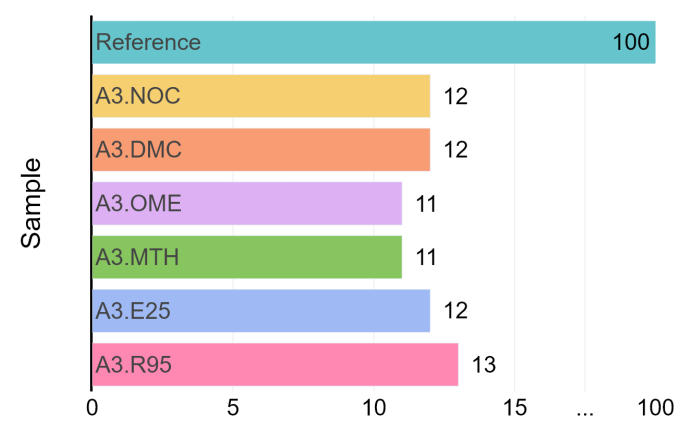

b) ZDDP residue $(\%)$

Figure 5. (a) Comparison of respective oxidation values after the parametric artificial aging experiment. (b) Comparison of respective residual antiwear additive (ZDDP) content values after the parametric artificial aging experiment. Reference: Shell Helix Ultra ECT C2/C3 0W-30.

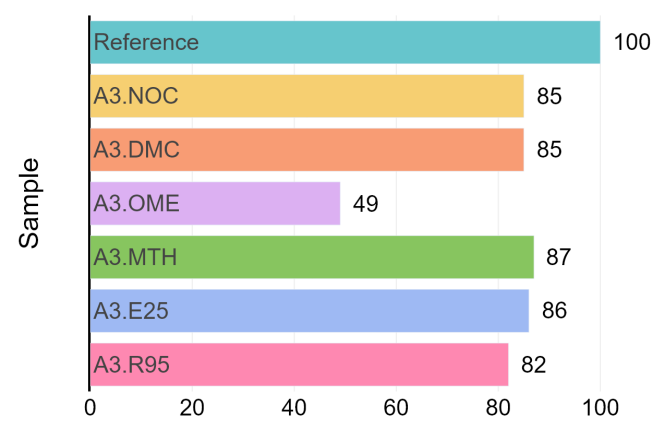

a) Aminic antioxidant residue (\%)

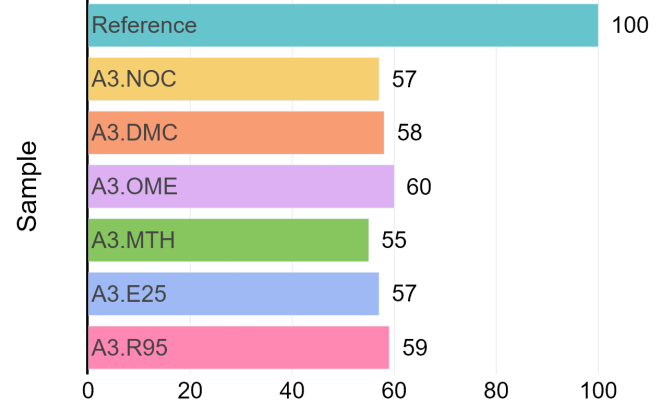

b) Phenolic antioxidant residue (\%)

Figure 6. (a) Comparison of respective aminic antioxidant additive residues after the parametric artificial aging experiment. (b) Comparison of respective phenolic antioxidant additive residues after the parametric artificial aging experiment. Reference: Shell Helix Ultra ECT C2/C3 0W-30.

A general increase in kinematic viscosity was measured at $40{ }^{\circ} \mathrm{C}$ (Figure 7a). The sample contaminated with $\mathrm{OME}_{3-5}$ shows the highest value in comparison, with a rather significant $30 \%$ increase over the reference sample. This difference is similarly pronounced at $100{ }^{\circ} \mathrm{C}$ (Figure $7 \mathrm{~b}$ ), with a $10 \%$ higher value than the reference. A nearly identical tendency can be observed with DMC contamination, with slightly lower absolute increase over the reference. This increase in viscosity could be attributed to increased polymerization due to the catalytic effect of $\mathrm{OME}_{3-5}$ and DMC.

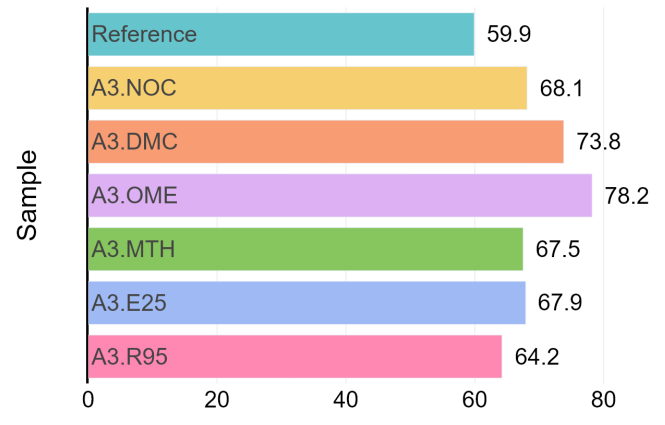

a) Kinematic viscosity @ $40^{\circ} \mathrm{C}\left(\mathrm{mm}^{2} / \mathrm{s}\right)$

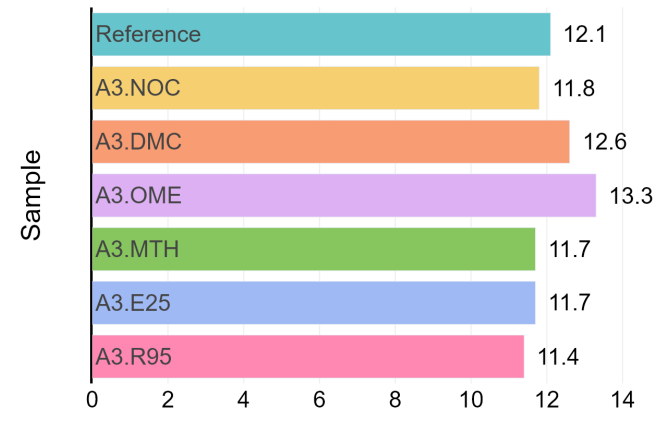

b) Kinematic viscosity @ $100^{\circ} \mathrm{C}\left(\mathrm{mm}^{2} / \mathrm{s}\right)$

Figure 7. (a) Comparison of kinematic viscosity at $40{ }^{\circ} \mathrm{C}$ after the parametric artificial aging experiment. (b) Comparison of kinematic viscosity at $100{ }^{\circ} \mathrm{C}$ after the parametric artificial aging experiment. Reference: Shell Helix Ultra ECT C2/C3 0W-30.

Regarding viscosity index (Figure 8a), all samples measured around 172 units, which denotes a $15 \%$ decrease compared to the reference. There seems to be no distinguishable 
effect of contaminant type on viscosity index. TBN values show (Figure $8 b$ ) an identical trend to residual aminic antioxidants. $\mathrm{OME}_{3-5}$ contamination leads to a noticeable reduction in total base number compared to other fuel types.

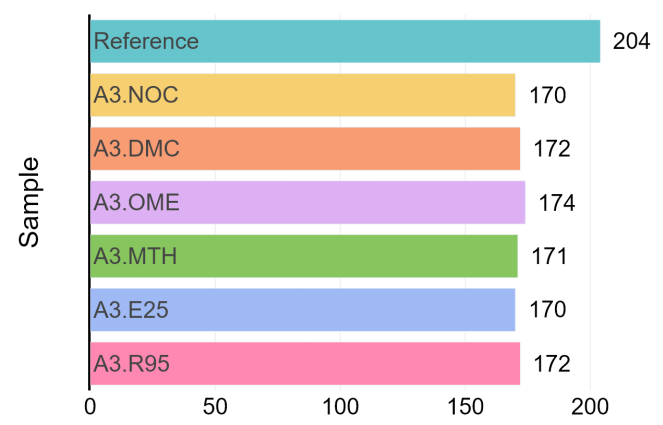

a) Viscosity Index (-)

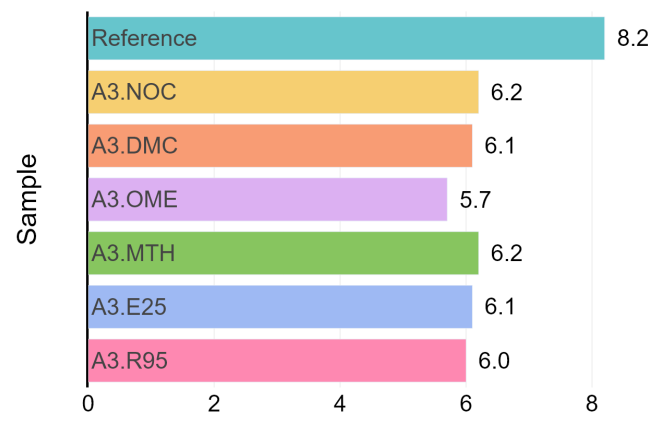

b) Total Base Number (mgKOH/g)

Figure 8. (a) Comparison of viscosity index after the parametric artificial aging experiment. (b) Comparison of total base number (TBN) after the parametric artificial aging experiment. Reference: Shell Helix Ultra ECT C2/C3 0W-30.

Overall, the aging study involving alternative fuels as contaminants in the oil during aging yielded interesting results regarding the amount of residual aminic antioxidant and kinematic viscosity values for the sample contaminated with $\mathrm{OME}_{3-5}$. The experienced drop in antioxidant content and elevated kinematic viscosity at both $40{ }^{\circ} \mathrm{C}$ and $100{ }^{\circ} \mathrm{C}$ suggest an underlying chemical reaction, which needs further attention and detailed analysis, but exceeds the scope of the current study.

\subsection{Comparative Oil Chemistry Analysis}

The focus of this comparison is to show the similarities and differences between fieldaged and artificially aged oil samples, and to prove or disprove the validity of the artificial aging methodology.

Figure 9 presents a clear separation of short-range and long-range vehicles in terms of usage patterns as expected. Further analysis reveals that vehicles with similar characteristics tend to exhibit similar usage profiles. Vehicles with a diesel engine or a $185 \mathrm{~kW}$ gasoline engine are larger passenger cars (E-segment and J-segment according to [19]), which show higher average speed and trip length values and a high mileage during the sampling period. These vehicles have comparably more passenger and luggage space, hence were taken for long $(>100 \mathrm{~km})$ trips involving highways more often. Vehicles with a $221 \mathrm{~kW}$ gasoline engine have a smaller chassis (C-segment [19]) and show mixed usage. Vehicles of this group have a fairly high performance variant of the gasoline engine but lack luggage space, and were therefore taken for short $(<100 \mathrm{~km})$ trips. Two outliers can be identified based on Figure 9:

- Vehicle 3 is a long-range vehicle, which had to undergo maintenance during the fleet study, hence it only registered a mileage of $1300 \mathrm{~km}$.

- Vehicle 9 has the largest luggage space from the three C-segment cars, hence it was taken for long trips for a comparable number of times to large vehicles.

Based on this graph it can be concluded that drivers preferred to take larger vehicles for longer trips involving high-speed road infrastructure (i.e., highway), whereas highperformance compact vehicles were used in urban areas and on main roads. 


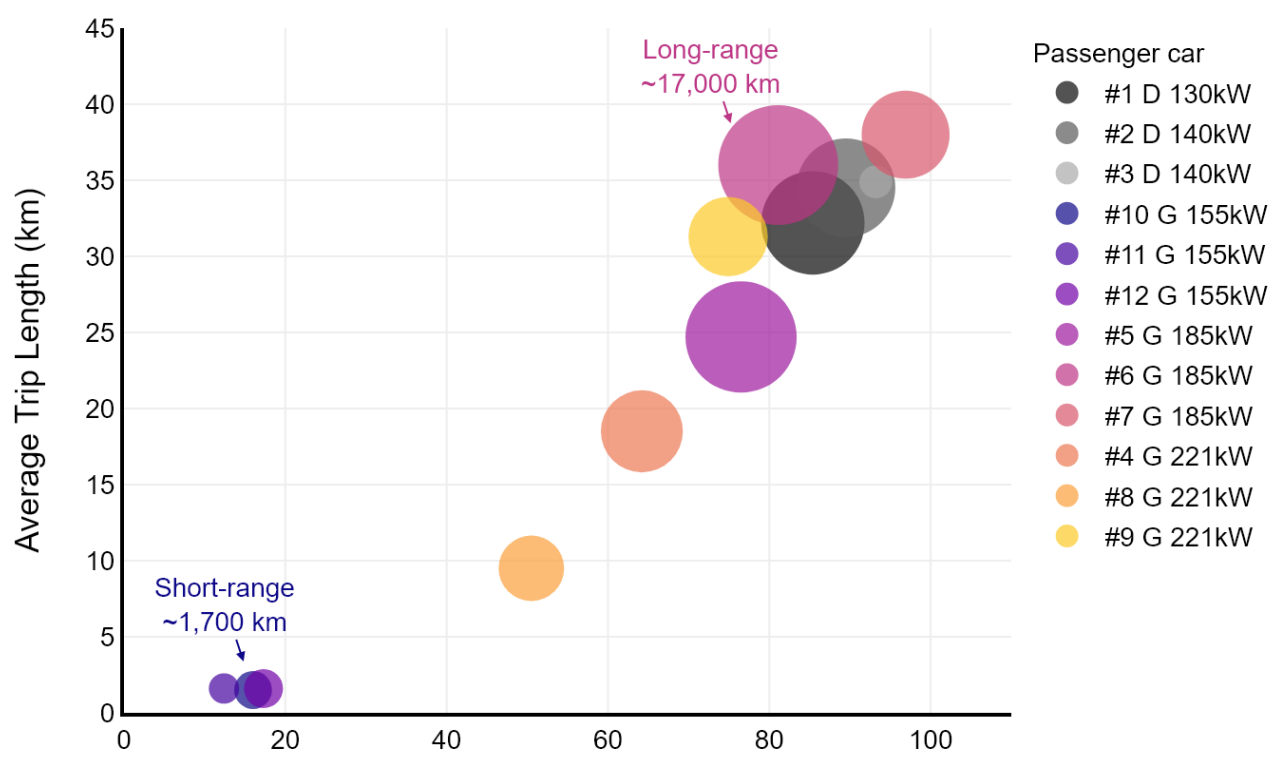

Average Vehicle Speed $(\mathrm{km} / \mathrm{h})$

Figure 9. A visual representation of vehicle properties and usage through the course of the fleet study. Bubble size represents the mileage of each corresponding vehicle. Legend colors represent engine type and power.

Results of the PCA are presented in Figure 10. The contribution of each feature to the principal components is shown on a loading plot (Figure 10a). Samples from the fleet study are shaded by mileage (Figure 10b) and power (Figure 10c) on the respective score plots. Artificially aged samples are marked with upward (parametric study) and downward (contaminant study) facing triangles (Figure 10d). Reference oil samples are marked for both the fleet (circle) and artificial aging (triangle) experiments. A total explained variance of $87.56 \%$ was established, with the 1st principal component (PC1) contributing to $64.61 \%$ of the explained variance. The 2 nd principal component (PC2) explains $22.95 \%$ of variance in the measured values in this analysis. PC1 and PC2 are interpreted as linear combinations of previously mentioned features.

A deeper insight into the nature of in-use and artificial oil degradation can be gained by taking a look at the loadings for each feature and the corresponding loading plot (Figure 10a). The direction of each plotted vector shows how the corresponding feature correlates to the two principal components. The length of each plotted vector signifies the strength of correlation between each feature and the principal components. For PC1 the first three features in the order of strength of correlation are residual antiwear additive content (ZDDP, $r=0.687$ ), residual phenolic antioxidant additive content (pheAO, $r=0.475$ ) and residual aminic antioxidant additive content ( $\mathrm{amiAO}, r=0.424)$. The first three features for PC2 in order of correlation strength are viscosity index (VI, $r=0.729)$, kinematic viscosity at $40{ }^{\circ} \mathrm{C}(\mathrm{V} 40, r=0.429)$ and residual phenolic antioxidant additive content (pheAO, $r=0.389$ ).

According to the loadings it can be concluded that PC1 corresponds to residual additive content, whereas PC2 corresponds to the change in oil viscosity. Taking into account the previously presented values of the reference sample as well as the artificially aged samples, it is reasonable to assume that $\mathrm{PC} 1$ is inversely proportional to the amount of antioxidant and antiwear additive residues, while PC2 is inversely proportional to viscosity. 


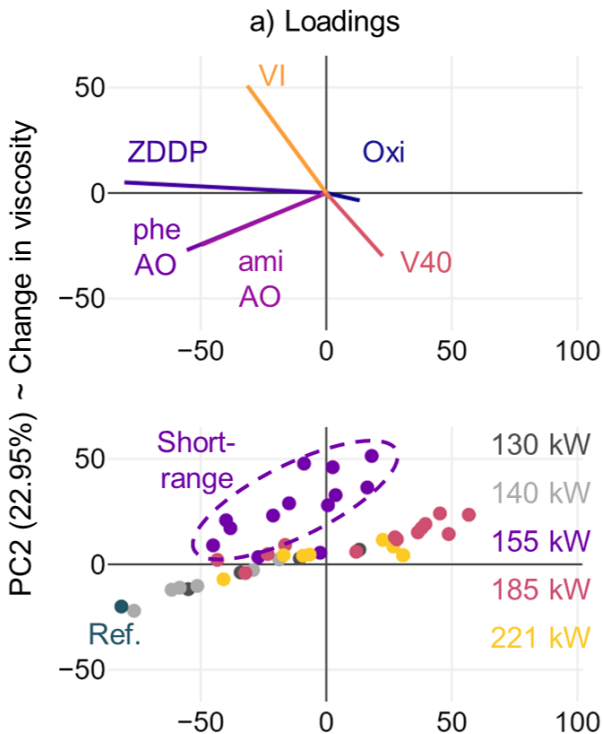

c) Score plot colored by power b) Score plot colored by mileage
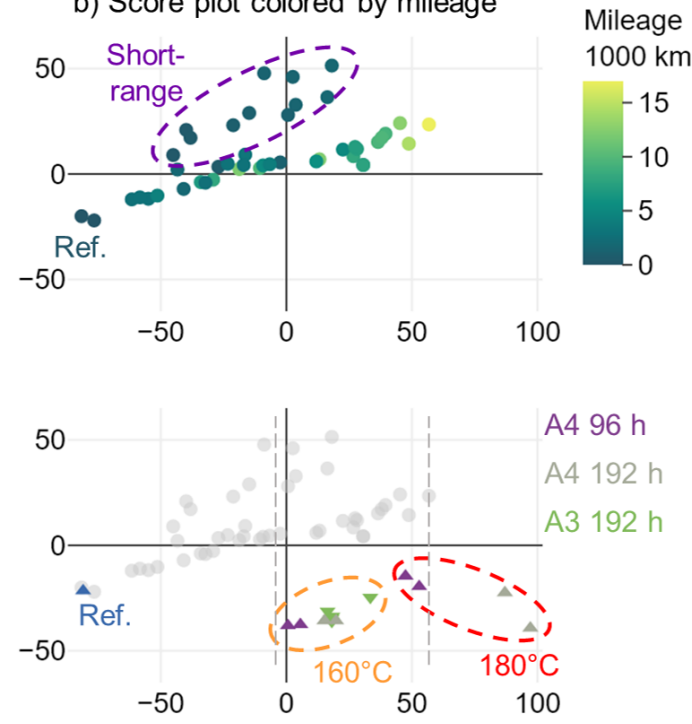

d) Score plot of artificially aged samples

PC1 (64.61\%) Residual additive content

Figure 10. Score plot of the principal component analysis with the corresponding loadings for each feature (a), displaying the results of the PCA on in-use $(\mathbf{b}, \mathbf{c})$ and artificially aged (d) engine oil samples. The corresponding unadulterated reference oils are marked for both studies.

As anticipated, higher mileage (Figure 10b) contributes to a significant decrease in additive content and a mild-to-moderate decrease in kinematic viscosity, which is in accordance with overall expectations. Interestingly, short-range and long-range vehicles show a clear separation in terms of chemical properties in the PCA. Samples from vehicles with low average trip length and average vehicle speed (short-range, Figure 9) show distinct PC2 values from long-range vehicles. However, more nuanced differences between vehicles-e.g., engine power-seem to have negligible effects on the investigated parameters (Figure 10c). The largest change in viscosity was registered by a $155 \mathrm{~kW}$ short-range vehicle with around $2000 \mathrm{~km}$ mileage, whereas the most significant drop in additive content was reported from a $185 \mathrm{~kW}$ long-range vehicle with approx. 17,000 km mileage. Most reported values scatter below these extrema, regardless of engine performance. This apparent discrepancy of engine power affecting oil degradation can be attributed to the fact that every engine derivate includes slight modifications to ensure long-term operation without failure. A 221 $\mathrm{kW}$ derivate in general has improved oil cooling and a slightly higher oil charge compared to a $155 \mathrm{~kW}$ derivate, in order to avoid overloading the lubricant. It is known from [11] that incorporating soot and wear metal content into the PCA leads to a clear separation of diesel vehicles. These were ignored in the current study, since the presented aging method is incapable of producing such properties.

Figure 10d presents PCA score values for the artificially aged samples in relation to the fleet study. This representation of the data gives a basic understanding of how artificially aged samples compare to in-use samples. In terms of antiwear and antioxidant additive residue (PC1) the artificially aged samples show comparable values, with a large number of observations from both studies falling into the region marked by dotted lines. Viscosity change (PC2), however, shows consistently higher values after the artificial aging procedure. This can be attributed to the fact that in-engine oil aging is highly influenced by fuel dilution, which was not considered in the case of the parametric aging experiments. The elevated temperature during artificial aging contributes to the evaporation of lighterend hydrocarbons and results in an increase in kinematic viscosity. As for the contaminated samples, the addition of fuels occurred at the start of each heating phase during the second stage of the experiment. It is theorized that most of the contaminant evaporates 
during the high temperature phase, hence a dilution at the end of the experiment cannot be measured by determining the viscosity of the sample. The mechanism of in-use fuel dilution follows a different pathway, where contamination occurs continuously and under moderate temperature (approx. $110^{\circ} \mathrm{C}$ ) inside the oil sump. Higher fuel dilution values are reported when a shorter test cycle is applied to an engine in a cold $\left(0^{\circ} \mathrm{C}\right)$ environment, while continuous operation for longer time periods yields equilibrium fuel dilution levels around $4 \%$ [20-22].

Figure 11 presents viscosity index values plotted against residual antiwear additive content. A similar separation to Figure 10 can be established, with artificially aged samples showing a lower viscosity index. All artificially aged samples register slightly below the in-use samples for antiwear additive content. This result is in accordance with the thermal decomposition phenomenon of ZDDP antiwear additives reported by [23-25]. In-use samples can exhibit temperatures well over $180^{\circ} \mathrm{C}$ in an operating internal combustion engine (e.g., piston ring and cylinder wall interaction in the TDC region [26]), however, these circumstances affect a restricted amount of lubricant at a time. Oil is in constant flow inside the engine between higher temperature $\left(200-250^{\circ} \mathrm{C}\right)$ load bearing regions (e.g., top piston ring nut) and accumulates in lower temperature $\left(<110^{\circ} \mathrm{C}\right)$ relief regions (i.e., the oil sump). According to the presented results the specific thermo-oxidative load during the artificial aging procedure appears to be moderately higher as exhibited by the lubricant under its common operating conditions.

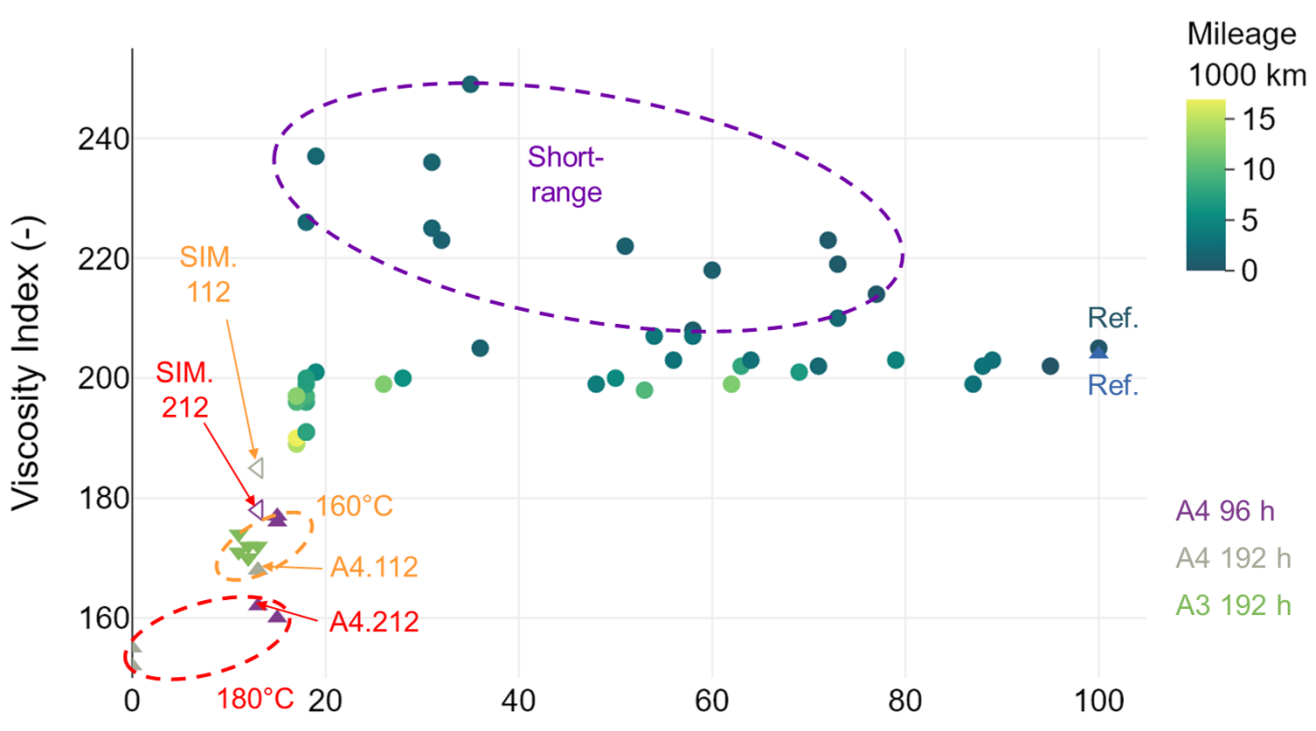

\section{Residual antiwear additive content (\%)}

Figure 11. Viscosity index plotted against residual antiwear additive content for both artificially aged batches and samples from the fleet study.

A discernible variation in values and a better overall correlation of artificially aged and in-use samples can be seen in Figure 12. Regarding residual phenolic antioxidant content, all artificial aging samples exhibit values in the range of the in-use samples. Taking into account viscosity as well, samples from the A3 series (contaminated) all scatter between A4.111 and A4.112 (parametric). This further proves the reproducibility aspect of the aging procedure, since these samples were exposed to nearly identical conditions in the sense of temperature, air flow rate and initial sample volume during the corresponding experiments. Furthermore, a strong resemblance can be found between A4.212 and multiple in-use samples with around $7000 \mathrm{~km}$ mileage. 


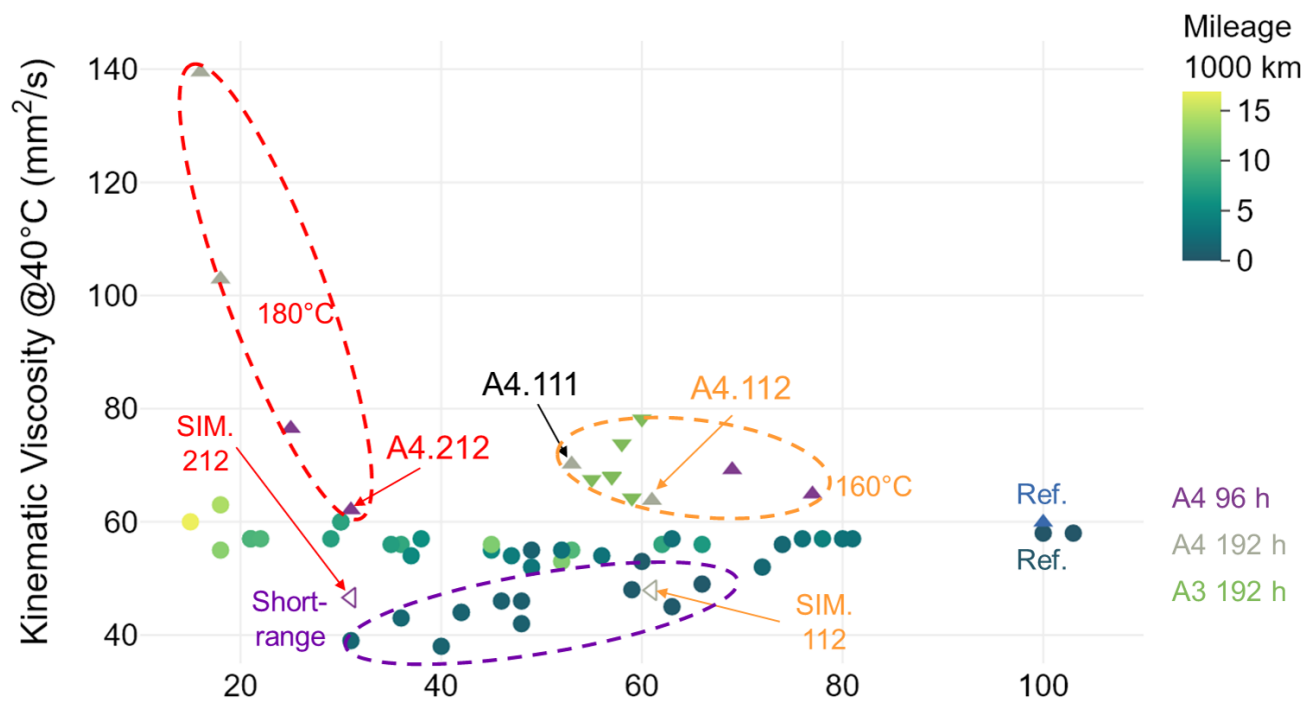

Residual phenolic antioxidant content (\%)

Figure 12. Kinematic viscosity at $40{ }^{\circ} \mathrm{C}$ plotted against residual phenolic antioxidant additive content for both artificially aged batches and samples from the fleet study.

As presented in [11], a fuel dilution of around $3.7 \mathrm{~m} \%$ was found in selected samples of short-range vehicles. Furthermore, it was shown in a simple dilution experiment [27] that mixing $3.7 \mathrm{~m} \%$ RON 95 gasoline into the reference oil results in comparable kinematic viscosity and viscosity index values to the corresponding properties of a selected in-use sample with identical dilution. This further suggests that the change in viscosity in the case of field study samples can be partly attributed to fuel dilution. Hence, the differences between in-use and artificial samples in terms of PC2, viscosity index and kinematic viscosity can be explained by contrasting boundary conditions in the fuel dilution process for the artificial and real-life scenarios. In order to simulate the accumulation of fuel in the lubricant and the resulting change in viscosity, values of A4.112 and A4.212 were offset by a factor of 1.1 [11] for viscosity index and 0.75 [11] for kinematic viscosity at $40{ }^{\circ} \mathrm{C}$. The resulting simulated values are plotted in Figures 11 and 12, labeled as SIM.112 and SIM.212. The simulated higher permanent dilution-i.e., fuel administered after the aging, thus not evaporated due to the thermal load-reduces viscosity and improves viscosity index. With this consideration, both simulated samples present values that are close to the observations of the fleet study in terms of viscosity index, with SIM.112 showing fairly good correlation to short-range samples regarding phenolic antioxidants and kinematic viscosity as well. This suggests that parameter set A4.112, with a post-aging fuel dilution of $3.7 \mathrm{~m} \%$, could be utilized to create batches of artificially aged oil with similar properties to used oils from short-range vehicles. Regarding oil aging in long-range vehicles, the parameter set A4.212 could be applicable for creating small batches of artificially aged lubricant samples from SAE 0W-30 engine oils under laboratory conditions, which represent a used engine oil condition of around $7000 \mathrm{~km}$ mileage in terms of kinematic viscosity $@ 40{ }^{\circ} \mathrm{C}$ and residual phenolic antioxidant content, and resemble used oil conditions regarding residual ZDDP antiwear additive content.

\section{Conclusions}

This study aimed at presenting the applicability of the previously developed aging equipment and implemented procedure for laboratory-scale artificial engine oil aging, as well as the validity of resulting artificially aged samples in terms of oil condition compared to in-use engine oil samples. An SAE $0 \mathrm{~W}-30$ grade commercially available fully synthetic engine oil from Shell was used as the basis of aging experiments. Numerous artificially 
aged samples were produced with varying aging parameters and contaminant types and analyzed through conventional FTIR spectroscopy, viscosimetry and titration. Results were compared to the reference in terms of oxidation, residual antioxidant and antiwear additive content, total base number, kinematic viscosity and viscosity index. Artificially aged samples were also compared to in-use engine oil samples from a previous study using PCA analysis. The following observations were made based on the presented results:

- The parametric aging study showed that the main contributor to engine oil oxidation is aging temperature, followed by aging time. Sample volume, therefore specific thermal load, also has a discernible effect; however, air flow rate during aging appears to have only a minor impact.

- Both temperature levels of the parametric aging study appear to cause nearly identical degradation of ZDDP antiwear additives, with comparable levels of residual content at $160{ }^{\circ} \mathrm{C}$ and $180^{\circ} \mathrm{C}$ after $96 \mathrm{~h}$ of aging. Samples still showed similar values after $192 \mathrm{~h}$ at $160^{\circ} \mathrm{C}$, whereas no residual antiwear additive content was found after $192 \mathrm{~h}$ at $180^{\circ} \mathrm{C}$. This can be explained with the lack of temperature stability above $120^{\circ} \mathrm{C}$ of ZDDP [28] as an engine oil additive.

- Kinematic viscosity increased during the parametric aging experiment, which could be a result of polymerized oxidation products and/or thermal polymerization of the engine oil. This observation is in accordance with [29], and is briefly mentioned in [30]. However, a more detailed analysis is necessary to prove this assumption.

- The contaminated aging study yielded interesting results regarding the amount of residual aminic antioxidant and kinematic viscosity values for the sample contaminated with $\mathrm{OME}_{3-5}$. The experienced drop in antioxidant content and elevated kinematic viscosity at both $40^{\circ} \mathrm{C}$ and $100{ }^{\circ} \mathrm{C}$ suggest an underlying chemical reaction, which needs further attention and detailed analysis, but exceeds the scope of the current study.

- Compared to in-use engine oil samples, both artificial aging studies show comparable results in terms of residual phenolic antioxidant content. Based on the presented results the parameter set $\mathrm{A} 4.212\left(180^{\circ} \mathrm{C}, 1 \mathrm{~L} / \mathrm{min}, 200 \mathrm{~mL}, 96 \mathrm{~h}\right)$ can be recommended for small-scale artificial aging of engine oils. This aging procedure can create an oil condition similar to an in-use engine oil sample after $7000 \mathrm{~km}$ of mixed on-road usage in terms of kinematic viscosity at $40{ }^{\circ} \mathrm{C}$, residual phenolic antioxidant content and residual ZDDP antiwear additive content.

Author Contributions: Conceptualization, A.L.N. and I.Z.; methodology, A.L.N.; resources, J.R.-B.; data curation, A.L.N.; writing—original draft preparation, A.L.N.; writing—review and editing, I.Z. and J.R.-B.; visualization, A.L.N.; supervision, I.Z. and J.R.-B. All authors have read and agreed to the published version of the manuscript.

Funding: Presented results were partially realized in research projects with financial support from the participating project partners and the Austrian COMET program (Project InTribology, No. 872176). The COMET program is funded by the Austrian Federal Government and concerning InTribology by the provinces of Lower Austria and Vorarlberg.

Institutional Review Board Statement: Not applicable.

Informed Consent Statement: Not applicable.

Data Availability Statement: Data regarding artificially aged engine oil samples presented in this study are available on request from the corresponding author.

Acknowledgments: The authors would like to thank the kind support of fellow researchers at AC2T research $\mathrm{GmbH}$.

Conflicts of Interest: The authors declare no conflicts of interest. The funders had no role in the design of the study; in the collection, analyses, or interpretation of data; in the writing of the manuscript, or in the decision to publish the results. 


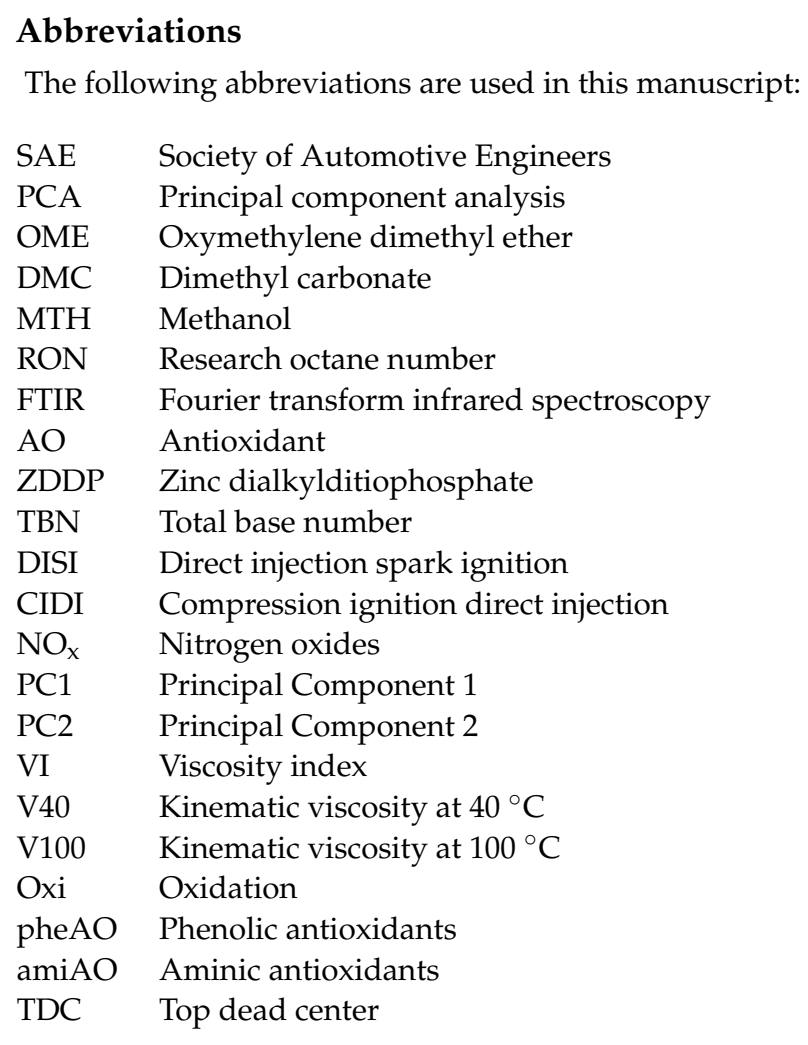

\section{References}

1. Baldwin, R. Toyota Is Finally Making an Electric Vehicle, Plans More. 2020. Available online: https://www.caranddriver.com/ news /a34896309/toyota-electric-cars-plans-revealed/ (accessed on 8 April 2021).

2. Blanco, S.; Honda, V.W. Making Wildly Different Bets on Our Electric Future. 2019. Available online: https://www.caranddriver. $\mathrm{com} /$ news/a30350065/honda-vw-electric-cars-future/ (accessed on 8 April 2021).

3. Reuters. BMW Aims for $20 \%$ of Its Vehicles to be Electric by 2023. Available online: https://www.reuters.com/article/bmwelectric-idUSKBN2910GV (accessed on 8 April 2021).

4. European Comission. 2030 Climate \& Energy Framework. 2014 Available online: https://ec.europa.eu/clima/policies/ strategies/2030_en (accessed on 8 April 2021).

5. Rudnick, L.R. Lubricant Additives, 2nd ed.; CRC Press: Boca Raton, FL, USA, 2017. [CrossRef]

6. Torbacke, M.; Rudolphi, Å.K.; Kassfeldt, E. Lubricants; John Wiley \& Sons, Ltd.: Chichester, UK, 2014. [CrossRef]

7. Richard Booser, E. CRC Handbook of Lubrication and Tribology; CRC Press: Boca Raton, FL, USA, 1993; Volume III. [CrossRef]

8. Dörr, N.; Agocs, A.; Besser, C.; Ristić, A.; Frauscher, M. Engine Oils in the Field: A Comprehensive Chemical Assessment of Engine Oil Degradation in a Passenger Car. Tribol. Lett. 2019, 67. [CrossRef]

9. Nagy, A.L. Development of an artificial aging process for automotive lubricants. Spring Wind 2019, 2019, 771-775.

10. Nagy, A.L.; Zsoldos, I. Artificial Aging of Ultra-low Viscosity Lubricant Samples on a Programmable Oil Aging Rig. In VAE 2020: Vehicle and Automotive Engineering 3; Springer: Singapore, 2021; pp. 139-147. [CrossRef]

11. Agocs, A.; Nagy, A.L.; Tabakov, Z.; Perger, J.; Rohde-Brandenburger, J.; Schandl, M.; Besser, C.; Dörr, N. Comprehensive assessment of oil degradation patterns in petrol and diesel engines observed in a field test with passenger cars-Conventional oil analysis and fuel dilution. Tribol. Int. 2021. [CrossRef]

12. Singer, A.; Ruck, W.; Krahl, J. Influence of Different Biogenic Fuels on Base Oil Aging. SAE Tech. Pap. 2014, 2014. [CrossRef]

13. Nagy, A.L.; Knaup, J.; Zsoldos, I. A Review on the Effect of Alternative Fuels on the Friction and Wear of Internal Combustion Engines; Jármai, K., Bolló, B., Eds.; Vehicle and Automotive Engineering 2; Springer International Publishing: Cham, Switzerland, 2018; pp. 42-55.

14. ASTM D7042-21. Standard Test Method for Dynamic Viscosity and Density of Liquids by Stabinger Viscometer (and the Calculation of Kinematic Viscosity); ASTM International: West Conshohocken, PA, USA, 2021. [CrossRef]

15. ASTM D2270-10(2016). Standard Practice for Calculating Viscosity Index from Kinematic Viscosity at $40{ }^{\circ} \mathrm{C}$ and $100{ }^{\circ} \mathrm{C}$; ASTM International: West Conshohocken, PA, USA, 2016. [CrossRef]

16. ISO 3771:2011. Petroleum Products-Determination of Base Number-Perchloric Acid Potentiometric Titration Method; International Organization for Standardization: Geneva, Switzerland, 2011.

17. Härtl, M.; Seidenspinner, P.; Jacob, E.; Wachtmeister, G. Oxygenate screening on a heavy-duty diesel engine and emission characteristics of highly oxygenated oxymethylene ether fuel OME1. Fuel 2015, 153, 328-335. [CrossRef] 
18. Iannuzzi, S.E.; Barro, C.; Boulouchos, K.; Burger, J. POMDME-diesel blends: Evaluation of performance and exhaust emissions in a single cylinder heavy-duty diesel engine. Fuel 2017, 203, 57-67. [CrossRef]

19. ISO 3833:1977. Road Vehicles-Types-Terms and Definitions; International Organization for Standardization: Geneva, Switzerland, 1977.

20. Sagawa, T.; Fujimoto, H.; Nakamura, K. Study of fuel dilution in direct-injection and multipoint injection gasoline engines. $S A E$ Tech. Pap. 2002. [CrossRef]

21. Kleiner, F.; Kaspar, M.; Artmann, C.; Rabl, H.P. Online Oil Dilution Measurement at GDI Engines. SAE Tech. Pap. 2014, 2014. [CrossRef]

22. Hakeem, M.; Anderson, J.; Surnilla, G.; Yamada, S.S. Characterization and speciation of fuel oil dilution in gasoline direct injection (DI) engines. In Proceedings of the ASME 2015 Internal Combustion Engine Division Fall Technical Conference, ICEF 2015, Houston, TX, USA, 8-11 November 2015; Volume 1. [CrossRef]

23. Jones, R.B.; Coy, R.C. Chemistry of the Thermal Degradation of Zinc Dialkyldithiophosphate Additives. ASLE Trans. 1981, 24, 91-97. [CrossRef]

24. Peng, P.; Hong, S.Z.; Lu, W.Z. The degradation of zinc dialkyldithiophosphate additives in fully formulated engine oil as studied by P-31 NMR spectroscopy. Lubr. Eng. 1994, 50, 230-235.

25. Ferguson, S.; Johnson, J.; Gonzales, D.; Hobbs, C.; Allen, C.; Williams, S. Analysis of ZDDP Content and Thermal Decomposition in Motor Oils Using NAA and NMR. Phys. Procedia 2015, 66, 439-444. [CrossRef]

26. Mahle GmbH, Ed. Pistons and Engine Testing; Vieweg+Teubner Verlag: Wiesbaden, Germany, 2012. [CrossRef]

27. Agocs, A.; Nagy, A.L.; Perger, J.; Rohde-Brandenburger, J.; Ronai, B.; Besser, C.; Dörr, N. Feldstudie über die Motorölalterung in Personenkraftwagen; Tribologie und Schmierungstechnik; Expert Verlag: Tübingen, Germany, 2020; Volume 5-6, pp. 78-79.

28. Safe Handling Guidelines for ZDDP Components and Blends. 2015. Available online: https://www.americanchemistry.com/ ProductsTechnology/Petroleum-Additives-Safety-Task-Group-PAST/Safe-Handling-Guidelines-for-ZDDP-Componentsand-Blends.pdf (accessed on 26 March 2021).

29. Johnson, M.D.; Korcek, S.; Jensen, R.K.; Gangopadhyay, A.K.; Soltis, E.A. Laboratory Assessment of the Oxidation and Wear Performance Capabilities of Low Phosphorus Engine Oils. SAE Tech. Pap. 2001. [CrossRef]

30. Besser, C.; Agocs, A.; Ronai, B.; Ristic, A.; Repka, M.; Jankes, E.; McAleese, C.; Dörr, N. Generation of engine oils with defined degree of degradation by means of a large scale artificial alteration method. Tribol. Int. 2019, 132, 39-49. [CrossRef] 